\title{
SEPTIMIO SEVERO EN ANAZARBO
}

The father of the poet Oppian was banished from Anazarbos because he didn't meet the Emperor Septimius Severus with the whole city. An analysis of the political context after the campaigns against Pescennius Niger and an analysis of the meaning of the receptions to the emperors makes easy to understand this notice apparently trivial.

La guerra civil promovida por Septimio Severo y Pescenio Nigro conmocionó la próspera vida de las ciudades de Asia Menor y Siria en los años 193 y 194 d.C. Rastros del conflicto son, por una parte, las sanciones de Severo a las ciudades que apoyaron a P. Nigro, a las que privó de sus muy queridos títulos honoríficos, y, por otra, las concesiones de privilegios y títulos a las ciudades que se habian mostrado partidarias de él durante la guerra ${ }^{~}$. Sin embargo, no fue ésta una guerra en la que las ciudades griegas tomaran partido por uno u otro de los pretendientes al trono de forma fundada. Tampoco tenían los contendientes un proyecto político que les diferenciara y estimulara una toma de decisión ponderada. A todos resultaba evidente que Didio Juliano era un mal emperador y debía ser eliminado ${ }^{2}$, y tal necesidad prevalecía sobre cualquier otra consideración, como tuvo ocasión de oír Septimio Severo de boca de un senador (C.D., LXXIV 9, 1-2). Tales circunstancias justifican la inconsistencia con la que las ciudades se inclinaron hacia un bando u otro, y éste es el sentido del texto de Herodiano donde

1 F. Gascó, Casio Dión. Sociedad y politica en tiempo de los Severos, Madrid 1988, pp. 44-48, 59-62. Para el tema de la rivalidad por títulos entre ciudades griegas y la bibliografia sobre ello cf. F. Gascó, "Casio Dión y la rivalidad de las ciudades griegas», G. Pereira (ed.), Actas del Primer Congreso Peninsular de Historia Antigua, I, Santiago de Compostela 1988, pp. 135-145; F. Gascó, Ciudades griegas en conflicto, Madrid 1990. En este último trabajo presento un estudio de las razones que motivaron las rivalidades por titulos y rango entre las ciudades griegas de época altoimperial, el tema está en la base de los comportamientos de Anazarbo y los privilegios que obtuvo.

${ }^{2}$ Gascó, Casio Dión, pp. 36-39. 
explica que apoyaron a uno $u$ otro de los contendientes de manera un tanto ocasional y que bastaba que una ciudad optara por uno de los candidatos para que la vecina y rival se decidiera por el adversario (Hdn., III 2, 7-9). Son conocidas algunas de las vicisitudes de estas ciudades, tanto las represalias a las que fueron sometidas, como el proceso que las urbes degradadas siguieron con Septimio Severo y sus sucesores para recuperar sus títulos y privilegios, así como, en el caso de las partidarias de Severo, las honras, títulos y agones con las que fueron distinguidas.

Es de suponer, no obstante, que en las ciudades no se actuó con pleno acuerdo, más cuando al principio hubo de parecer indiferente quién pudiera resultar vencedor, y así un buen número de personas sorprendidas en un lugar u otro, como sucede en todas las guerras civiles, se debieron ver forzadas a admitir algo en lo que no participaron con convicción o que simplemente les era ajeno. Tenemos de estas actitudes personales pocas referencias, de hecho se reducen a dos: la del senador Casio Clemente, que confiesa paladinamente ante Severo que no conocía a ninguno de los contendientes y su partido en favor de Nigro era fruto del azar (C.D., LXXIV 9, 1-2) y la de Agesilao, padre del poeta Opiano $^{3}$, referencia objeto del comentario que sigue.

La noticia sobre Agesilao está en la colección de biografias editadas por A. Westermann el siglo pasado ${ }^{4}$ :

Cuando Opiano tenia aproximadamente treinta años, Severo, emperador de los romanos, visitó Anazarbo. A pesar de que todos los ciudadanos debían salir al encuentro del emperador, Agesilao descuidó hacer acto de presencia, ya que vivía a lo filósofo y menospreciaba las vanidades. Tomándolo a mal, el emperador le exilió a la isla de Melita en el Adriáticos.

A pesar de lo escueta que es la noticia, hay en ella aspectos dignos de ser comentados, sin los que la referencia se pierde como un detalle insustancial.

La visita de Severo a la ciudad de Anazarbo tuvo lugar probablemente en el 194 d.C., cuando se dirigía hacia Siria ${ }^{6}$ y estaba justificada

${ }^{3}$ Opiano de Anazarbo que compuso en hexámetros Cynegetica, por la que se cuenta que Caracala le dio una moneda de oro por cada verso, y, quizá, Halieutica. Cf. la ed. de W.F. Mair, Loeb, 1928.

4 Biographoi, uitarum scriptores graeci minores, Braunschweig 1845, p. 63, líneas 7 ss.

5 Sobre la situación en la que quedaban los bienes de los relegati in insulam, que conservaban sus propiedades y el derecho de testar, cf. D., XXVIII 1, 8 (F. Millar, The Emperor in the Roman World, Ithaca, Nueva York, 1977, p. 167).

- Además de las Puertas Cilicias había otra entrada en Cilicia en la parte Este de las montañas del Tauro que desembocaba en Anazarbo, cf. D. Magie, Roman 
en primer término por el interés de Septimio Severo en poner orden y dejar constancia con su presencia de su victoria en las distintas ciudades de las provincias de Asia Menor tras la derrota de P. Nigro. Pero la visita podría tener un motivo menos de ocasión fundado en el interés estratégico de Cilicia, encrucijada imprescindible de caminos que habían de ser transitados por los ejércitos que pasaran de Asia Menor a Siria o a la inversa ${ }^{7}$, algo que con los partos en el horizonte Severo hubo de tener presente.

Ésta es la razón por la que Septimio Severo lleva a cabo su visita a la ciudad de Anazarbo, pero, ¿por qué reacciona de una forma tan enérgica por la indiferencia de un ciudadano que vivía a lo filósofo? Hay un conjunto de prácticas y circunstancias que permiten una explicación del suceso.

La llegada de un emperador a una ciudad era una ocasión singularísima tanto para la ciudad como para el propio emperador ${ }^{8}$. El amplio significado que tenía se fue rodeando de un ceremonial que evolucionó desde finales del s. II d.C. hasta convertirse en un complejo ritual que hizo del aduentus imperial una auténtica ceremonia religiosa ${ }^{9}$. Para tiempos de los Severos, sobre todo para Caracala, hay referencias literarias y representaciones a través de monedas de los distintos aspectos del ritual que ya por la época rodeaba las visitas imperiales a las ciudades orientales. Así, por ejemplo, cuando Caracala llegó a las afueras de Alejandría en diciembre del 215 d.C. Casio Dion nos cuenta que le salieron al encuentro los "primeros» de la ciudad acompañados de «objetos sagrados inefables» (LXXVII 22, 2) ${ }^{10}$. Esta recepción encuentra imágenes paralelas en las representaciones que aparecen en las monedas de Pérga-

Rule in Asia Minor, Princeton 1950, p. 1154; C.R. Whittaker, Herodian, I, p. 270 s.; A. Birley, Septimius Severus, the African Emperor, Londres 1971, p. 181; H. Halfmann, Itinera principum. Geschichte und Typologie der Kaiserreisen im Römischen Reich, Sttutgart 1986, p. 219 s. (no menciona la visita de Severo a Anazarbo, pero sí discute el recorrido del emperador por Asia Menor y Cilicia en dirección a Siria); Gascó, Casio Dión, p. 46. Sin embargo, R. Ziegler señala también como posible la fecha de la segunda expedición contra los partos, Städtisches Prestige und kaiserliche Politik. Studien zum Festwesen in Ostkilikien im 2. un 3. Jahrhundert n.Chr., Düsseldorf 1985 , p. $78 \mathrm{~s}$.

7 Ziegler, o.c , pp. 13-15.

${ }^{8}$ Halfmann en o.c., pp. 111-142, recoge los distintos aspectos que rodean las visitas de los emperadores a las ciudades, tanto desde la perspectiva de los emperadores como de las propias ciudades, en especial a través de las aristocracias de las mismas.

${ }^{9} \mathrm{~S}$. MacCormack, "Change and Continuity in Late Antiquity: the Ceremony of the Adventus", Historia 21, 1972, pp. 721-752; Halfmann, o.c., pp. 143-148.

10 La visita precede a la matanza de los alejandrinos por Caracala, un suceso con unas causas nada claras, Gascó, o.c., pp. 84-86. 
mo con ocasión de la visita de Caracala en donde los magistrados ofrecen una estatuilla del dios Asclepio al emperador en las puertas de la ciudad ". Pero la larga serie de monedas cívicas de Pérgamo conmemorativa de la visita de Caracala nos ofrece también imágenes del emperador haciendo sacrificios en el Asclepion de Pérgamo vestido como gran sacerdote, o imágenes de los templos (Augusto, Asclepio y Trajano) reparados por el emperador a resultas de la visita. Estas imágenes contribuyen a comprender el significado religioso, político y social que tales ocasiones tenían tanto para la ciudad como para el emperador. Para la ciudad, esto es, para la aristocracia que la gobernaba, se convertía en una oportunidad de excepción para mostrar al emperador su aprecio y lealtad y como contrapartida para pedirle privilegios y concesiones varias, aspecto este último nada desdeñable en un contexto como el que existía en Asia Menor de rivalidad entre ciudades que pugnaban por obtener títulos honoríficos y prioridades de rango. Por su parte el emperador se asociaba con los dioses de la ciudad, con los que al mezclarse en templos y cultos quedaba unido a los elementos de referencia más sagrados de las ciudades, concedía privilegios, entraba en contacto con magistrados y el pueblo y ocasionalmente asumía de forma honorífica alguna magistratura ${ }^{12}$. La voluntad de los emperadores era recibir una confirmación de su poder a través del consentimiento de la ciudad en pleno (consensus omnium) ${ }^{13}$, algo que se estimaba vital para su legitimidad. Las ausencias o indiferencias en este ambiente de tensión producido por el encuentro entre la ciudad - con sus dioses y mandatarios al frente y el pueblo al fondo - y el emperador visitante hubieron de considerarse inadmisibles, en especial cuando las circunstancias políticas eran difíciles, como obviamente hubieron de serlo después de la derrota de P. Nigro, y el poder, que todavía tenía que revalidarse, se había alcanzado de forma discutida. Hay un suceso parecido a éste que estamos comentando de Agesilao, aunque acaecido casi veinte años atrás y con un emperador más benévolo, que prueba las suspicacias y reacciones que se producian ante incomparecencias de ciudadanos no justificadas en las recepciones a los príncipes. Me refiero al encuentro que finalmente tuvieron Marco Aurelio y Elio Aristides en Esmirna. Recuérdese el interés, con un reproche implícito cuando por fin lo saludó, que mostró

$"$ K. Harl, Civic Coins and Civic Politics in the Roman East (A.D. 180-275), Berkeley-Los Angeles-Londres 1987, pl. 23.3.

${ }_{12}$ Halfmann, o.c., ibidem; Harl, o.c., p. 52 ss.

${ }^{13}$ H.U. Instinsky, "Consensus Universorum", Hermes 75, 1940, pp. 265-278; K. Oehler, "Der consensus omnium als Kriterium der Wahrheit in der antiken Philosophie und der Patristikm"', $A \& A$ 10, 1961, pp. 103-129. 
Marco Aurelio al comprobar que el sofista Elio Aristides no se encontraba entre «la multitud de los que habian acudido a tributarle homenaje» y cómo mandó expresamente a buscarlo a los hermanos Quintilio, cuando visitó la ciudad de Esmirna en su recorrido por Oriente después del levantamiento de Avidio Casio (Philostr., VS 582 s.) ${ }^{14}$.

Con este conjunto de referencias como trasfondo el exilio de Agesilao a una isla de la costa dálmata cobra un significado que va más allá de una reacción despótica de Septimio Severo ante lo que pudo entender como desdén. La visita del emperador era a la ciudad de Anazarbo, comprometida desde hacía mucho tiempo en una contienda por títulos con Tarso. En consecuencia para la mencionada ciudad era importante un respaldo decidido a la recepción en la que se debía mostrar la vinculación de la ciudad a la causa de Septimio Severo, en especial tras la derrota de P. Nigro, y con intención de capitalizar el pronto apoyo de la ciudad a la causa del emperador victorioso. La coyuntura era especialmente apta para Anazarbo, pues Tarso, su eterna rival y metrópoli de Cilicia, no debió mostrarse partidaria de Severo de una manera tan pronta ${ }^{15}$. El éxito alcanzado por la ciudad en las aspiraciones que esperaba cumplir con la visita del emperador, se evidencia con la excepcional recompensa que recibió durante el reinado de Septimio Severo en forma de dos neocorías dedicadas al culto imperial ${ }^{16}$. Al mismo tiempo para Severo era fundamental asentar su victoria sobre P. Nigro con sólidas adhesiones, para lo que concedió la organización de agones conmemorativos (epineikia) ${ }^{17}$, recompensó a las ciudades que le habían apoyado y que con el "consenso de todos los ciudadanos" ratificaban la legitimidad adquirida por las armas.

Agesilao, padre del poeta Opiano, escogió la peor ocasión para dejar ver su indiferencia filosófica ante las ambiciones y glorias mundanas; ni sus paisanos ni el nuevo emperador hubieron de sufrirlo con paciencia y por ello hubo de expiar su inoportunidad en la isla de Melita.

Fernando Gascó

${ }^{14}$ Cf. F. Gascó, "The Meeting between Aelius Aristides and Marcus Aurelius in Smyrna", AJP 110, 1989, pp. 471-478.

is Ziegler (o.c., p. 79) sugiere que la proximidad de las tropas de Nigro en las Puertas Cilicias hubieron de obligar a Tarso a actuar de manera más precavida.

${ }_{16}$ Ziegler, o.c., pp. 74-79. Los privilegios no sólo eran recompensas para la ciudad que los recibía, sino también desaires para la ciudad rival.

${ }_{17}$ Ziegler, o.c., p. 75. 